\title{
What is missed out in EFL Assessing at Tertiary Level in China?
}

\author{
Huijie Li \\ School of Foreign Languages \\ Harbin Institute of Technology \\ Harbin, China \\ lihuijiehit@163.com
}

\begin{abstract}
This paper aims to make an analysis on EFL assessing at tertiary level in China by putting it in a global assessment environment. The paper firstly introduces the root of assessment in education, i.e. three paradigms: positivist, interpretative and critical, and its philosophical underpinnings: ontology, epistemology, and methodology assumptions. The paper also makes term clarification of test, testing, assessment, and evaluation. Three models of language competence are presented in order to give description of EFL construct. The EFL assessing in China is mainly prescribed in the official document College English Curriculum Requirements. The frequently used test types and techniques are summarized in the paper as well. By comparing the Requirements and the test techniques with the previously mentioned assessing principle, it is expected to find out what is missed out in EFL assessing in China.
\end{abstract}

Keywords-language education; EFL; tertiary level; assessment

\section{INTRODUCTION}

EFL Testing can be regarded as a means of educational research through which learners' language abilities are measured or investigated. In this field, what to test and how to test are always the heatedly-discussed topics. In China, especially at the tertiary level, there is a big gap in terms of testing methodology between pedagogical practice and theoretical models. So what might be missed out?

To answer the question, we need to trace back to the three paradigms of educational research: positivist, interpretative and critical. By examining the philosophical underpinnings of the paradigms, it is possible to get a clue on the nature of testing; therefore, knowing what paradigm you are going to take is the start point of deciding what to test and how to test.

I will begin with the ontology, epistemology, and methodology assumptions of each paradigm, with which we get to know the characteristics of each paradigm. Then I will make term clarification as to test, testing, assessment, and evaluation. Next, I will introduce three models as the construct of EFL assessing and types of assessment methods. By showing the college English teaching objective in the Curriculum Requirements and giving a list of popular testing techniques in English tests at tertiary level, I can dramatize the gap between the pedagogical practice and the construct.

\section{PHILOSOPHICAL UNDERPINNINGS OF THREE PARADIGMS}

Paradigm was first termed by Thomas Kuhn (1972) as "an overall theoretical research framework." More specifically, a paradigm can be defined as "a loose collection of logically related assumptions, concepts or propositions that orient thinking and research." Simply put, one's view of reality and being is called ontology and the view of how one acquires knowledge is termed epistemology. Grix warns that people who want to conduct clear, precise research and evaluate other's research need to understand the philosophical underpinnings that inform their choice of research questions, methodology, methods and intentions [1]. Therefore, how one views the constructs of social reality and knowledge affects how they will go about uncovering knowledge of relationships among phenomena and social behavior and how they evaluate their own and other's research.

TABLE I. CATEGORIES OF PARADIGMS

\begin{tabular}{|l|l|l|l|}
\hline positivist & interpretative & critical \\
\hline ontology & $\begin{array}{l}\text { Reality can be } \\
\text { captured by our } \\
\text { senses and predicted. }\end{array}$ & $\begin{array}{l}\text { Reality is indirectly based on } \\
\text { individual interpretation and } \\
\text { is subjective }\end{array}$ & $\begin{array}{l}\text { reality is socially constructed through } \\
\text { media, institutions and society }\end{array}$ \\
\hline epistemology & $\begin{array}{l}\text { Knowledge is } \\
\text { objective. }\end{array}$ & $\begin{array}{l}\text { Knowledge is gained } \\
\text { through personal experience. }\end{array}$ & $\begin{array}{l}\text { "What counts as worthwhile knowledge } \\
\text { is determined by the social and positional } \\
\text { power of the advocates of that } \\
\text { knowledge" (Cohen et al, 2007. p. 27). }\end{array}$ \\
\hline methodology & experiments & interpretation & $\begin{array}{l}\text { looking for the "political and economic } \\
\text { foundations of our construction of } \\
\text { knowledge, curriculum, and teaching." } \\
\text { (Gage, 1989, p. 5) }\end{array}$ \\
\hline
\end{tabular}

Choosing a paradigm is important because it decides how you look at your research target and in what way you are going to achieve it.

\section{TERM CLARIFICATION}

It is frequently asked how the terms "test, testing, assessment, evaluation" differentiate from one another. The table shows their definition and you can see each term has its own focus. 
TABLE II.

\begin{tabular}{|l|l|}
\hline Term & Definition \\
\hline Test & any procedure for measuring ability, knowledge, or performance \\
\hline Testing & $\begin{array}{l}\text { the use of tests, or the study of the theory and practice of their use, development, } \\
\text { evaluation, etc. }\end{array}$ \\
\hline Assessment & $\begin{array}{l}\text { the measure of the ability of a person or the quality or success of a teaching } \\
\text { course, etc. }\end{array}$ \\
\hline Evaluation & $\begin{array}{l}\text { in general, the systematic gathering a information for purposes of decision } \\
\text { making. Evaluation uses both quantitative methods, qualitative methods and value } \\
\text { judgments. }\end{array}$ \\
\hline
\end{tabular}

Assessment aims at forming judgements about individuals through measurement of achievements, abilities, attitudes, etc. Evaluation aims to judge and make decision. The general goal of assessment aims at improving student learning [2]. Assessment requires the gathering of evidence of student performance over a period of time to measure learning and understanding. Evidence of learning could take the form of dialogue, journals, written work, portfolios, and tests along with many other learning tasks. Evaluation on the other hand occurs when a mark is assigned after the completion of a task, test, quiz, lesson or learning activity. In the UK, assessment takes the form of what students submit such as project reports, or written papers.

\section{What TO ASSESS: THREE MODELS}

Three models will be applied to illustrate the construct of language testing.

\section{A. Lado's Higher Values Model}

No thoughtful teacher of foreign languages would want to say that the only value in learning a language is the practical control of it as a signaling system. Other and higher values are assumed to result from the proper study of another language (Lado, R. Language Testing, 1961; Chapter 21 Testing the higher values). Four values are related to foreign language study that seems to lie beyond mere mastery of a signaling system: education itself; insight into own language; insight into a foreign culture; insight into own culture [3]. Perhaps we cannot be certain that any value beyond language will be attained, but we can be reasonably sure that those values exist and that they have been sought in the study of foreign languages through the ages. Since we cannot be certain that every language class produces these additional values, it is important that they should be tested.

\section{B. Bloom's Taxonomy for Education Objectivesd}

S. Bloom, and his colleagues, in the late of 1950's, published "A taxonomy for educational objectives", which provides enormous enlightenment on language teaching and testing, too. The taxonomy categorizes educational objectives in 6 groups/levels:

- knowledge

- comprehension

- application

- analysis

- synthesis

- evaluation
According to Anderson \& Krathwohl's revised edition in 2001[4], knowledge dimension and cognitive process dimension both have details as follows:

Knowledge dimension

Factual knowledge

Knowledge of terminology

Knowledge of specific details and elements

Conceptual knowledge

Knowledge of classification and categories

Knowledge of principles and generalizations

Knowledge of theories, models and structures

Procedural knowledge

Knowledge of subject-specific skills and algorithms

Knowledge of subject-specific techniques and methods

Knowledge of criteria for determining when to use appropriate procedures

Metacognitive knowledge

Strategic knowledge

Knowledge about cognitive tasks

Self-knowledge

Cognitive Process dimension

Remember:

Recognizing: identifying

Recalling: retrieving

Understand:

Interpreting: clarifying, paraphrasing, representing, translating

Exemplifying: illustrating, instantiating

Classifying: categorizing, subsuming

Summarizing: abstracting, generalizing

Inferring: concluding, extrapolating, interpolating, predicting

Comparing: contrasting, mapping, matching

Explaining: constructing models

Apply:

Executing: carrying out

Implementing: using

Analyze:

Differentiating: discriminating, distinguishing, focusing, selecting

Organizing: finding, coherence, outlining, integrating, parsing, structuring

Attributing: deconstructing

Evaluate:

Checking: coordinating, detecting, monitoring, testing Critiquing: judging

Create:

Generating: hypothesizing

Planning: designing

Producing: constructing

\section{Bachman's CLA Model}

The highlight of Bachman's CLA lies in his new definition of "language competence", which is composed of organizational competence and pragmatic competence [5]. 


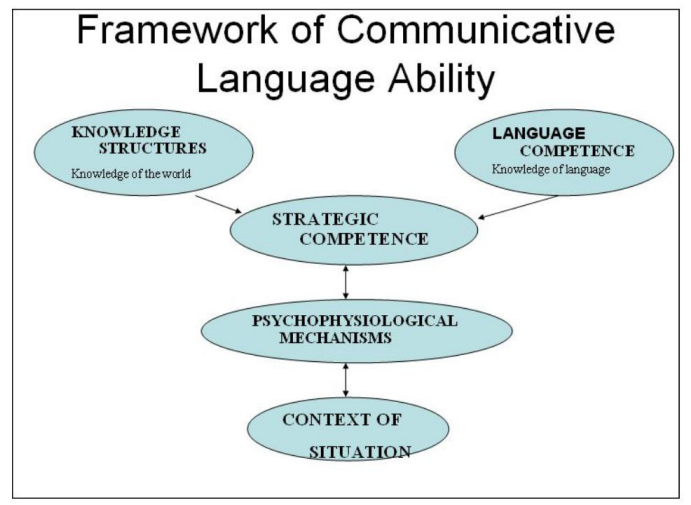

Fig. 1. Bachman's CLA Framework

Bachman's description of language competence is comprehensive enough and is regarded as the construct of language testing by many scholars.

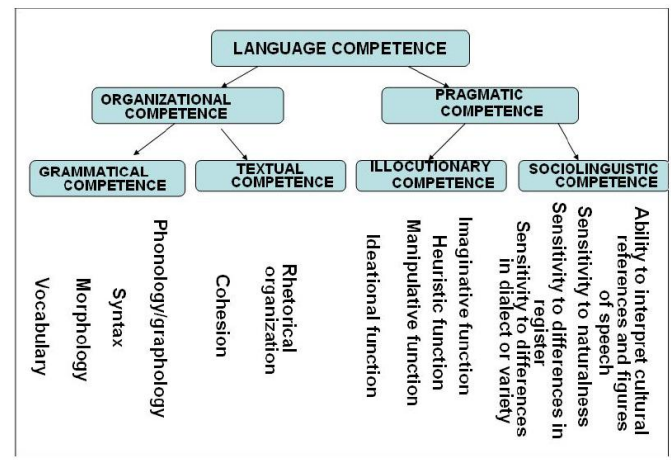

Fig. 2. Bachman's Language Competence Framework

\section{EFL LEARNING STATUS AT TERTIARY LEVEL IN CHINA}

Now let's have a look at the EFL learning status of the students at tertiary level in China. According to the National College English Curriculum Requirements, [11] the intermediate level requirements are prescribed in detail.

Taking reading as an example, we can see clearly the quantitative demand in terms of reading speed.

If we make a comparison between the theoretical models and the curriculum requirement, it is clearly seen that there is a wide gap ahead of us preventing us from getting close to the real significance of EFL learning.

\section{A. College English Curriculum Requirements}

It is stated in the Requirements that "The objective of College English is to develop students' ability to use English in a well-rounded way, especially in listening and speaking, so that in their future studies and careers as well as social interactions they will be able to communicate effectively, and at the same time enhance their ability to study independently and improve their general cultural awareness so as to meet the needs of China's social development and international exchanges." [11]

\section{B. Intermediate Requirements}

However, the requirements for the intermediate level students overstate the statistic descriptions of the subskills, in terms of listening, speaking, reading, writing and translation. It's also alert that some numbered scales are too general while others are too specific. For example, when it comes to listening, it says students should grasp the main idea and relevant details of longer TV programs with a speed of from 150 to $180 \mathrm{wpm}$. It is hard to define how long is a longer TV programe. Meanwhile the specific speed requirement is surely not the only index to describe and determine how well a student could present his or her listening skill. A student's listening skill is supposed to include his or her uderstanding of the cultural knowledge of the target language.

\section{HOW TO TEST}

What you are going to test determines the methodology how you assess students' EFL ability or competence. There are several types of assessment as follows:

- Content-based assessment

- Task-based assessment

- Standards-based/criteria-based assessment

- Performance-based assessment

- Curriculum-based assessment

- Competence-based assessment

Most of the tests are trying to adopt competence-based assessment, but as a matter of fact, the tests we administer at the end of each term are basically curriculum-based assessment [6].

Competence-based assessment is a form of assessment that is derived from a specification of a set of outcomes; that so clearly states both the outcomes - general and specific - that assessors, students and interested third parties can all make reasonably objective judgments with respect to student achievement or non-achievement of these outcomes.

In pedagogical context, there are various assessment methods [7]:

1) Standardized Exams

2) Locally Developed Exams

3) Performance Measures

- Essays

- Oral presentations

- Oral exams

- Exhibitions

- Performances

- Products

- Research papers

- Poster presentations

4) Portfolios

- Learning Portfolios

- Assessment Portfolios

- Showcase Portfolios

- Performance Portfolios

- Personal Portfolios 
- Proficiency/Competency Portfolios

- Process Portfolios

- Developmental Portfolios

However, frequently-used techniques in EFL testing at tertiary level in China include

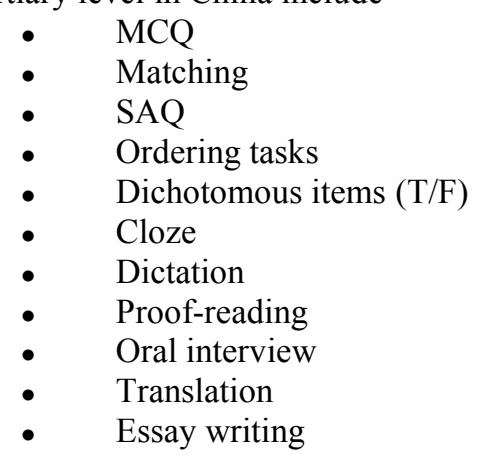

From the list mentioned above, it can be concluded that we are focusing too much on the scores of the tests and ignoring the collection of process evidences that show students' mastery of English.

\section{CONCLUSIONS}

It's easy to see the gap between the existent situation of tertiary EFLin China and the outlook of the advancement of language assessment in the world where experts focus on how to make tests reliable and valid, how to assess learners' communicative proficiency accurately, how to make classroom testing fun and how to evaluate learner oral skills accurately.

Mismatch between teaching syllabus and testing syllabus has led to irrelevant curriculum and evaluation [8]. Problems of over-emphases on quantitative assessment have led to disregard for qualitative assessment [9]. Balanced attention should be given to both quantitative and qualitative assessment. Evaluation impact of testing on the learners should be both constructive and positive. In addition, learners' communicative proficiency should be assessed accurately. It's never too much to give weight to integrative skill test, reliable grading of written tests and the assessment of students' learning progress [10].

\section{ACKNOWLEDGMENT}

The paper is sponsored by the research project granted by HIT in 2017, Developing the Academic Vocabulary Module.

\section{REFERENCES}

[1] J. Grix, Introducing the Key Research Paradigms, In book: The Foundations of Research, pp.77-100, 2010.

[2] J. Alderson, C. Clapham, and D. Wall, Language Test Construction and Evaluation, Beijing: Foreign Language Teaching and Research Press. 2000 .

[3] R. Lado, Language Testing, 1961.

[4] L. Anderson and D. Krathwohl, A taxonomy for learning, teaching, and assessing: A revision of Bloom's Taxonomy of Educational Objectivities, NY: Longman, 2001.

[5] L. Bachman, Fundamental Considerations in Language Testing, Shanghai: Shanghai Foreign Language Education Press. 1999.

[6] G. Henning, Language Testing. Newbury House Publishers, 1987.

[7] A. Hughes, Testing for Language Teachers. Cambridge: CUP, 1989.

[8] C. Weir, Understanding and Developing Language Tests. NY: Prentice Hall, 1993.

[9] C. Weir, Communicative Language Testing. Englewood Cliffs, NJ: Prentice Hall, 1990.

[10] R. Wood, Assessment and Testing: A Survey of Research Beijing: Foreign Language Teaching and Research Press, 2001.

[11] College English Curriculum Requirements, 2007, Shanghai: Shanghai Foreign Language Education Press. 2000. 